\title{
Weekly low-dose treatment with intravenous iron sucrose maintains iron status and decreases epoetin requirement in iron-replete haemodialysis patients
}

\author{
Daniela Schiesser ${ }^{1}$, Isabelle Binet ${ }^{2}$, Dimitrios Tsinalis ${ }^{2}$, Michael Dickenmann $^{3}$, Gérald Keusch ${ }^{4}$, \\ Markus Schmidli ${ }^{5}$, Patrice M. Ambühl ${ }^{6}$, Liudmila Lüthi ${ }^{6}$ and Rudolf P. Wüthrich ${ }^{6}$ \\ Cantonal Hospitals of ${ }^{1}$ Walenstadt, ${ }^{2}$ St Gallen and ${ }^{5}$ Herisau, ${ }^{4}$ Waid City Hospital, University Hospitals ${ }^{3}$ Basel and \\ ${ }^{6}$ Zürich, Switzerland
}

\begin{abstract}
Background. Haemodialysis patients need sustained treatment with intravenous iron because iron deficiency limits the efficacy of recombinant human epoetin therapy in these patients. However, the optimal intravenous iron maintenance dose has not been established yet.

Methods. We performed a prospective multicentre clinical trial in iron-replete haemodialysis patients to evaluate the efficacy of weekly low-dose $(50 \mathrm{mg})$ intravenous iron sucrose administration for 6 months to maintain the iron status, and to examine the effect on epoetin dosage needed to maintain stable haemoglobin values in these patients. Fifty patients were enrolled in this prospective, open-label, single arm, phase IV study.

Results. Forty-two patients $(84 \%)$ completed the study. After 6 months of intravenous iron sucrose treatment, the mean ferritin value showed a tendency to increase slightly from $405 \pm 159$ at baseline to $490 \pm 275 \mu \mathrm{g} / 1$ at the end of the study, but iron, transferrin levels and transferrin saturation did not change. The haemoglobin level remained stable $(12 \pm 1.1$ at baseline and $12.1 \pm 1.5 \mathrm{~g} / \mathrm{dl}$ at the end of the study). The mean dose of darbepoetin alfa could be reduced from 0.75 to $0.46 \mu \mathrm{g} / \mathrm{kg} /$ week; epoetin alfa was decreased from 101 to $74 \mathrm{IU} / \mathrm{kg} /$ week; and the mean dose of epoetin beta could be reduced from 148 to $131 \mathrm{IU} / \mathrm{kg} /$ week at the end of treatment.

Conclusions. A regular $50 \mathrm{mg}$ weekly dosing schedule of iron sucrose maintains stable iron stores and haemoglobin levels in haemodialysed patients and allows considerable dose reductions for epoetins. Low-dose intravenous iron therapy may represent an optimal approach to treat the continuous loss of iron in dialysis patients.
\end{abstract}

Correspondence and offprint requests to: Rudolf $\mathrm{P}$. Wüthrich, Clinic for Nephrology, University Hospital Zürich, Rämistrasse 100, CH-8091 Zürich, Switzerland. Email: rudolf.wuethrich@usz.ch
Keywords: anaemia; epoetins; haemodialysis; iron sucrose; outcome

\section{Introduction}

Iron deficiency is common in haemodialysis patients and limits the efficacy of treatment with epoetin [1]. Intravenous iron therapy is, therefore, required by almost all haemodialysis patients receiving epoetin to achieve the target haemoglobin in the most efficient way [2,3]. The National Kidney Foundation-Dialysis Outcomes Quality Initiative (NKF-DOQI) guidelines and the European Best Practice Guidelines (EBPG) advocate consistent detection and management of iron deficiency [4-7]. According to the revised EBPG for the management of anaemia in patients with chronic renal failure (2004), the serum ferritin target levels should be $>100 \mu \mathrm{g} / \mathrm{l}$ in all patients, but in practice, it is necessary to aim for a ferritin target of $200-500 \mu \mathrm{g} / 1$ to achieve this minimum level of $100 \mu \mathrm{g} / 1$ [7]. The new NKFDOQI guidelines recommend an even higher minimum ferritin level of $>200 \mu \mathrm{g} / \mathrm{l}$ in haemodialysis patients [5].

The EBPG and the NKF-DOQI guidelines do not give firm recommendations regarding the optimal dose and frequency of intravenous iron administration. Whereas it seems clear that iron-deficient haemodialysis patients need initial iron loading, the maintenance dosing schedule for iron-replete patients still needs to be defined [8]. Based on the results from several studies, a relatively broad dosing range from 25 to $150 \mathrm{mg} /$ week has been recommended [8-12]. With such a broad dosing range there is on the one side a risk of underdosing and also a risk of iron overload on the other [13].

The purpose of the present study was to examine whether a majority of iron-replete haemodialysis patients (ferritin in the range of $200-500 \mu \mathrm{g} / 1$ and transferrin saturation $>20 \%$ ) could maintain their iron 
status with a regularly applied low dose of intravenous iron sucrose $(50 \mathrm{mg}$ weekly). A secondary goal was to examine whether this iron treatment schedule could reduce the epoetin requirements.

\section{Methods}

\section{Study design}

The study was designed as a prospective, open-label, single arm, multicentre phase IV study and was performed in accordance with the International Conference of Harmonisation E3 Good Clinical Practice Guidelines and in compliance with the Helsinki declaration. Six hospital dialysis centres participated in the study, and all the local ethics committees approved the study. Written informed consent was obtained from all the patients.

The study population consisted of 50 stable maintenance haemodialysis patients. Male and female patients undergoing maintenance haemodialysis (2-3 sessions per week), 18-75 years of age, were included. All patients had to be ironreplete (serum ferritin 200-800 $\mu \mathrm{g} / \mathrm{l}$; transferrin saturation $20-50 \%$ ) and were required to display haemoglobin concentrations between 9.0 and $13.5 \mathrm{~g} / \mathrm{dl}$ on three successive occasions in the past 2 months before the study. All study patients received intravenous iron sucrose, in non-systematic fashion prior to the study inclusion. All study patients were also on epoetin therapy. Furthermore, hypertension was controlled with various blood pressure medications, and secondary hyperparathyroidism was controlled with phosphate binders and vitamin D preparations in all study subjects. The following criteria excluded the patients from the study: suspicion of iron overload (ferritin $>800 \mu \mathrm{g} / \mathrm{l}$, transferring saturation $>50 \%$ ), active inflammation or infection, malignancy, blood transfusions 3 months prior to and during the study.

\section{Study drug administration}

Patients received weekly doses of $50 \mathrm{mg}$ of iron sucrose $\left(\right.$ Venofer $^{\circledR}$ ) for a total of 24 doses. Iron sucrose was injected into the venous limb of the haemodialysis tubing system (slow intravenous push at a rate of $10 \mathrm{mg} / \mathrm{min}$ ). Iron therapy was stopped if the serum ferritin level exceeded $800 \mu \mathrm{g} / 1$, but was resumed when the serum ferritin had decreased below $600 \mu \mathrm{g} / \mathrm{l}$. Treatment failure was defined as a serum ferritin level which dropped below $100 \mu \mathrm{g} / 1$ despite continuous iron sucrose treatment.

\section{Study parameters}

Demographic baseline data (age, sex, ethnicity, height, weight and body mass index) were collected at the screening visit. Concomitant medications were also assessed. The epoetin dosage was not subjected to a defined treatment algorithm, but was adjusted in order to maintain the haemoglobin value that was recorded at inclusion. The epoetin dosage and application schedule was recorded throughout the study, and was averaged per month. Mean monthly baseline epoetin doses were calculated as the mean value of weeks -12 to -9 , weeks -8 to -5 and weeks -4 to -1 .
Iron parameters (serum ferritin, serum iron, transferrin and transferrin saturation), C-reactive protein (CRP) levels and haematological parameters (haemoglobin, haematocrit, red blood cell number and red cell indices (mean cellular volume, MCV; mean cellular haemoglobin, $\mathrm{MCH}$ and mean cellular haemoglobin concentration, $\mathrm{MCHC}$ ) were measured at the screening visit and then monthly, using standard laboratory procedures.

\section{Statistical analyses}

All efficacy parameters were analysed using descriptive statistics. Data are reported as mean \pm SD. SAS ${ }^{\circledR}$ Version 8.02 was the statistical software package used for all data analyses.

\section{Safety measurements}

The safety population included all patients who had received at least one dose of the study medication. Recurrent events occurring during haemodialysis (pruritus, leg pain) prior to study entry were recorded. When these events occurred with the same intensity during the study, they were not reported as adverse events. Blood pressure was measured $15 \mathrm{~min}$ before and $15 \mathrm{~min}$ after each iron sucrose injection as a measure of safety.

\section{Results}

The trial population consisted of 28 male and 22 female haemodialysis patients. The mean age was $58.2 \pm 12.8$ years, the mean weight $72.5 \pm 15.4 \mathrm{~kg}$ and the mean body mass index $25.8 \pm 4.6 \mathrm{~kg} / \mathrm{m}^{2}$. The study was completed by 42 of the 50 patients $(84 \%)$. Three patients $(6 \%)$ terminated the study earlier because of renal transplantation; three patients $(6 \%)$ had to be withdrawn from the study due to an adverse event which was not related to the study drug application (shunt malfunction; gastrointestinal bleeding; haemothorax); one patient $(2 \%)$ had to be excluded due to persistently high ferritin values; in one case $(2 \%)$, serum ferritin levels dropped below $100 \mu \mathrm{g} / \mathrm{ml}$ despite treatment with iron sucrose (treatment failure).

\section{Iron parameters}

All the patients were iron-replete at the start of the study. The mean ferritin values were in the optimal target range of $200-500 \mu \mathrm{g} / 1$ as defined by the EBPG. Mean ferritin values showed a non-significant trend to increase $(+17.3 \%)$ from $405 \pm 159 \mu \mathrm{g} / 1$ at baseline to $490 \pm 275 \mu \mathrm{g} / 1$ at the end of study (Table 1 ).

The iron and transferrin mean values did not change significantly, and mean transferrin saturation also did not change during the whole study period (Table 1). Together, these data show that iron stores increased slightly, but there was no sign of iron overload during the 6-month treatment phase.

CRP mean values were $6.8 \mathrm{mg} / 1$ at week $0,7.9 \mathrm{mg} / 1$ at week $9,8.4 \mathrm{mg} / 1$ at week 17 and $6.4 \mathrm{mg} / 1$ at week 25 . 
Table 1. Iron parameters of study population at baseline and during the 26 -week study period

\begin{tabular}{|c|c|c|c|c|}
\hline Week & Ferritin $(\mu \mathrm{g} / \mathrm{l})$ & Iron $(\mu \mathrm{mol} / \mathrm{l})$ & Transferrin (g/l) & TSAT $(\%)$ \\
\hline Screening & $405 \pm 159$ & $12.7 \pm 3.4$ & $1.7 \pm 0.3$ & $29.9 \pm 8.1$ \\
\hline Week 1 & $379 \pm 178$ & $13.3 \pm 4.1$ & $1.7 \pm 0.3$ & $31.3 \pm 11.8$ \\
\hline Week 5 & $430 \pm 194$ & $12.7 \pm 4.6$ & $1.7 \pm 0.3$ & $30.4 \pm 13.1$ \\
\hline Week 9 & $415 \pm 157$ & $12.9 \pm 4.5$ & $1.7 \pm 0.3$ & $31.0 \pm 10.9$ \\
\hline Week 13 & $420 \pm 170$ & $13.5 \pm 5.1$ & $1.7 \pm 0.3$ & $31.8 \pm 13.5$ \\
\hline Week 17 & $426 \pm 185$ & $12.7 \pm 3.9$ & $1.7 \pm 0.3$ & $30.1 \pm 9.7$ \\
\hline Week 21 & $472 \pm 173$ & $13.0 \pm 4.6$ & $1.7 \pm 0.2$ & $31.7 \pm 11.8$ \\
\hline End of study & $490 \pm 275$ & $13.3 \pm 4.0$ & $1.7 \pm 0.2$ & $31.2 \pm 10.5$ \\
\hline
\end{tabular}

Data are mean \pm SD. Mean ferritin levels increased by $17.3 \%$.

Table 2. Haematological parameters (haemoglobin and red cell indices [MCV, $\mathrm{MCH}, \mathrm{MCHC}$ )

\begin{tabular}{|c|c|c|c|c|}
\hline Week & $\mathrm{Hb}(\mathrm{g} / \mathrm{dl})$ & MCV (fl) & $\mathrm{MCH}(\mathrm{pg})$ & $\operatorname{MCHC}(\mathrm{g} / \mathrm{dl})$ \\
\hline Screening & $12.1 \pm 1.1$ & $95.0 \pm 6.8$ & $31.3 \pm 2.6$ & $33.0 \pm 1.2$ \\
\hline Week 1 & $12.2 \pm 1.1$ & $95.5 \pm 6.7$ & $31.4 \pm 2.5$ & $32.8 \pm 1.0$ \\
\hline Week 5 & $12.2 \pm 1.0$ & $95.4 \pm 6.1$ & $31.5 \pm 2.4$ & $32.9 \pm 1.2$ \\
\hline Week 9 & $12.4 \pm 1.1$ & $95.6 \pm 6.1$ & $31.6 \pm 2.4$ & $33.1 \pm 1.0$ \\
\hline Week 13 & $12.3 \pm 0.9$ & $96.5 \pm 6.6$ & $31.8 \pm 2.5$ & $32.9 \pm 1.2$ \\
\hline Week 17 & $12.4 \pm 1.0$ & $96.2 \pm 6.0$ & $31.8 \pm 2.5$ & $33.1 \pm 1.1$ \\
\hline Week 21 & $12.4 \pm 0.9$ & $95.9 \pm 6.2$ & $31.9 \pm 2.5$ & $33.2 \pm 1.1$ \\
\hline End of study & $12.1 \pm 1.5$ & $95.9 \pm 6.4$ & $31.7 \pm 2.4$ & $33.1 \pm 1.1$ \\
\hline
\end{tabular}

Data are mean \pm SD. Haemoglobin values remained stable and the red cell indices did not change.

Table 3. Monthly dosage of epoetins (standardized values)

\begin{tabular}{llll}
\hline Period & Darbepoetin alfa $(\mu \mathrm{g})$ & Epoetin alfa (IU) & Epoetin beta (IU) \\
\hline Number of patients & $n=14$ & $n=13$ & $n=19$ \\
Mean baseline (weeks -12 to -1$)$ & $221 \pm 159$ & $28578 \pm 13411$ & $36894 \pm 20404$ \\
Weeks 1-4 & $237 \pm 159$ & $24533 \pm 13405$ & $32310 \pm 20697$ \\
Weeks 5-8 & $195 \pm 122$ & $21867 \pm 14745$ & $32619 \pm 17912$ \\
Weeks 9-12 & $179 \pm 112$ & $24533 \pm 13384$ & $32190 \pm 15069$ \\
Weeks 13-16 & $172 \pm 112$ & $26133 \pm 15829$ & $32095 \pm 15437$ \\
Weeks 17-20 & $142 \pm 89$ & $28714 \pm 17144$ & $33368 \pm 14758$ \\
Weeks 21-24 & $136 \pm 90$ & $26769 \pm 18376$ & $33842 \pm 15643$ \\
\hline
\end{tabular}

Data are mean $\pm \mathrm{SD}$. The dosage for the three epoetins decreased by $38.5 \%$ [darbepoetin alfa (Aranesp $\left.{ }^{\circledR}\right)$, $6.3 \%$ [epoetin alfa $\left(\right.$ Eprex $\left.{ }^{\circledR}\right)$ ] and $8.3 \%$ [epoetin beta $\left(\right.$ Recormon $\left.{ }^{\circledR}\right)$ ].

These CRP values were in the normal range, indicating the absence of systemic inflammation and infection during the study.

\section{Haematological parameters}

The mean haemoglobin values did not change from the baseline screening period to the end of the study (Table 2). The mean haemoglobin of $12.1 \mathrm{~g} / \mathrm{dl}$ demonstrates that the patients were in the target range, as defined by the EBPG and K/DOQI guidelines. Table 2 also shows the red cell indices. MCV, MCH and $\mathrm{MCHC}$ were in the normal range during the entire study and did not change significantly.

\section{Epoetin requirement}

The changes in epoetin dosage are shown in Table 3. The monthly doses of the epoetins decreased markedly from the mean monthly values of weeks -12 to -1 (baseline phase) prior to the study to weeks 21 to 24 (assessment phase). The dosage for the three different epoetins decreased by $38.5 \%$ [darbepoetin alfa $\left(\right.$ Aranesp $\left.{ }^{\circledR}\right)$ ], 6.3\% [epoetin alfa $\left(\right.$ Eprex $\left.^{\circledR}\right)$ ] and 8.3\% [epoetin beta $\left(\right.$ Recormon $\left.^{\circledR}\right)$ ]. To confirm these data, we calculated the epoetin requirements in relation to the body weight. The mean dose of darbepoetin alfa was reduced with the iron treatment from 0.75 to $0.46 \mu \mathrm{g} /$ $\mathrm{kg} /$ week $(-38.7 \%)$. The mean dose of epoetin alfa was decreased from 101 to $74 \mathrm{IU} / \mathrm{kg} /$ week $(-26.7 \%)$. For epoetin beta, the mean dose could be reduced from 148 to $131 \mathrm{IU} / \mathrm{kg} /$ week $(-11.5 \%)$ at the end of treatment.

\section{Safety evaluation}

Another objective of this study was the evaluation of the safety of iron sucrose $\left(\right.$ Venofer $\left.^{\circledR}\right)$ given at a dosage 


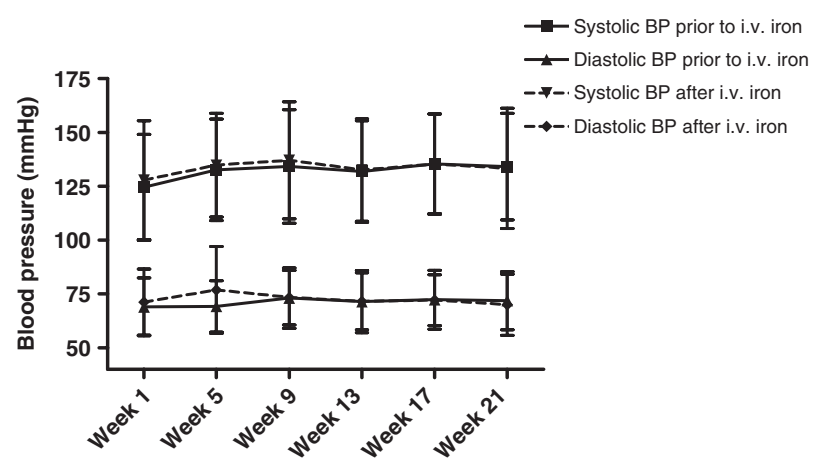

Fig. 1. Systolic and diastolic blood pressure $(\mathrm{mmHg}) 15 \mathrm{~min}$ prior to and $15 \mathrm{~min}$ after administration of the study drug are shown. Data are mean \pm SD.

of $50 \mathrm{mg}$ weekly. This reduced dosing regimen of iron sucrose was well tolerated by the patients. The intention to treat (ITT) population received 1062 iron sucrose doses, corresponding to a total amount of $53100 \mathrm{mg}$. Only one adverse event was classified as possibly related to Venofer $^{\circledR}$ by the investigators (swelling of soft tissue of unclear reason in different locations). None of the patients died. Hypotensive episodes were not reported. The mean systolic and diastolic blood pressures were unchanged prior to and after the iron sucrose administration throughout the study (Figure 1).

\section{Discussion}

The optimal intravenous iron dose required to maintain an iron-replete state in maintenance haemodialysis patients has not been defined yet. Therefore, a standardized approach to apply intravenous iron in iron-replete patients is lacking, and many dialysis centres have only insufficient treatment concepts $[13,14]$. Commonly, iron is applied only when iron deficiency is overt. Iron is then administered in relatively large doses, for weeks to months, and treatment is interrupted until ferritin levels drop below $100 \mu \mathrm{g} / 1$. This erratic treatment regime induces marked fluctuations of haemoglobin levels, and the subsequent epoetin dosages also need to be adapted frequently. Since there is a slight and continuous loss of blood and iron in haemodialysis patients, a better concept would be to apply intravenous iron as regularly as possible but in low dosage $[9,10]$.

Our study demonstrates that the regular application of $50 \mathrm{mg}$ of intravenous iron sucrose $\left(\right.$ Venofer $\left.^{\circledR}\right)$ is able to maintain and even to improve iron parameters in iron-replete haemodialysis patients. Additionally, this regimen allowed to markedly reduce the dosages of epoetin during the treatment. Therefore, iron sucrose can safely and conveniently be applied on a weekly basis. Together with a weekly application of epoetin, this improves anaemia management considerably by decreasing epoetin requirement, increasing adherence by patients and simplifying the application by the nursing staff.

Other investigators have tested various parenteral maintenance iron regimes [8-12,15-20]. However, most studies have been performed in iron-deficient patients or in patients with functional iron deficiency. Based on some of these studies, a recommendation of $2-3 \mathrm{~g}$ iron per year was calculated for haemodialysis patients. Therefore, a weekly $50 \mathrm{mg}$ dosing schedule (approximately $2.5 \mathrm{~g}$ per year) would seem to be appropriate for the majority of haemodialysis patients. Of course, this treatment scheme has limitations, and it may not be suitable for patients with bleeding, patients with inflammation and malnutrition and for patients with obvious iron deficiency. We speculate, however, that the regular $50 \mathrm{mg}$ weekly dose could be applied to $>80 \%$ of the stable haemodialysis patients.

Treatment beyond 6 months, however, would need monitoring to exclude long-term iron overload. This risk seems minor though, as many dialysis patients will eventually need some type of access procedure (percutaneous transluminal angioplasty or surgery) with subsequent blood loss, or may have some other form of bleeding (clotting of dialyser, gastro-intestinal bleeding). Thus, there will be increased blood loss, which will again require larger amounts of iron or even transfusions.

In summary, a weekly $50 \mathrm{mg}$ iron sucrose intravenous dosing scheme maintains stable iron parameters and haemoglobin values in iron-replete haemodialysis patients. The regular application of $50 \mathrm{mg}$ iron sucrose allows considerable epoetin dose reductions. Low-dose iron sucrose dosing may represent an optimal approach in treating the continuous loss of iron in haemodialysis patients.

Acknowledgements. The authors thank Vifor International AG (St Gallen, Switzerland) for the investigational drug and for financial support to perform this study.

Conflict of interest statement. R.P.W. is serving as a scientific consultant for Vifor International AG (St Gallen, Switzerland).

\section{References}

1. Bailie GR, Johnson CA, Mason NA. Parenteral iron use in the management of anemia in end-stage renal disease patients. Am J Kidney Dis 2000; 35: 1-12

2. Eschbach JW. Iron requirements in erythropoietin therapy. Best Pract Res Clin Haematol 2005; 18: 347-361

3. Nissenson AR, Charytan C. Controversies in iron management. Kidney Int Suppl 2003; 87: S64-S71

4. National Kidney Foundation. K/DOQI Clinical Practice Guidelines for Anemia of Chronic Kidney Disease, 2000. Am J Kidney Dis 2001; 37 [Suppl 1]: S182-S238

5. National Kidney Foundation. K/DOQI Clinical Practice Guidelines and Clinical Practice Recommendations for Anemia in Chronic Kidney Disease. Am J Kidney Dis 2006; 47 [Suppl 3]: $\mathrm{S} 58-\mathrm{S} 70$

6. Hörl WH, Jacobs C, Macdougall IC et al. European Best Practice Guidelines 14-16. Inadequate response to epoetin. Nephrol Dial Transplant 2000; 15: 43-50 
7. Locatelli F, Aljama P, Barany P et al. European Best Practice Guidelines Working Group. Revised European best practice guidelines for the management of anaemia in patients with chronic renal failure. Nephrol Dial Transplant 2004; 19 [Suppl 2]: iil-ii47

8. Besarab A, Amin N, Ahsan M et al. Optimization of epoetin therapy with intravenous iron therapy in hemodialysis patients. J Am Soc Nephrol 2000; 11: 530-538

9. Richardson D, Bartlett C, Will EJ. Optimizing erythropoietin therapy in hemodialysis patients. Am J Kidney Dis 2001; 38: 109-117

10. Hörl WH, Vanrenterghem Y, Canaud B et al. Optimal treatment of renal anaemia (OPTA): improving the efficacy and efficiency of renal anaemia therapy in haemodialysis patients receiving intravenous epoetin. Nephrol Dial Transplant 2005; 20 [Suppl 3]: iii25-iii32

11. MacDougall IC, Chandler G, Elston O, Harchowal J. Beneficial effects of adopting an aggressive intravenous iron policy in a hemodialysis unit. Am J Kidney Dis 1999; 34 [4 Suppl 2]: S40-S46

12. Chang $\mathrm{CH}$, Chiang SS. Reduction in erythropoietin doses by the use of chronic intravenous iron supplementation in iron-replete hemodialysis patients. Clin Nephrol 2002; 57: 136-141

13. Besarab A. Resolving the paradigm crisis in intravenous iron and erythropoietin management. Kidney Int 2006; 69 [Suppl 101]: S13-S18
14. Canavese C, Grill A, De Costanzi E et al. How to save money for erythropoietin therapy by changing from 'roller coaster' to continuous iron supplementation. Nephron 1999; 81: 362-363

15. Fishbane S, Frei GL, Maesaka J. Reduction in recombinant human erythropoietin doses by the use of chronic intravenous iron supplementation. Am J Kidney Dis 1995; 26: $41-46$

16. Canavese $\mathrm{C}$, Bergamo D, Ciccone $\mathrm{G}$ et al. Low-dose continuous iron therapy leads to a positive iron balance and decreased serum transferrin levels in chronic haemodialysis patients. Nephrol Dial Transplant 2004; 19: 1564-1570

17. Lin JL, Chang MY, Tan DT, Leu ML. Short-term small-dose intravenous iron trial to detect functional iron deficiency in dialysis patients. Am J Nephrol 2001; 21: 91-97

18. Descombes E, Fellay G. Improved response to erythropoietin therapy with long-term continuous iron supplementation. Nephron 2000; 84: 196-197

19. Kurihara I, Soma J, Nakayama K, Sato H, Saito T. Intravenous low-dose iron administration in hemodialysis patients treated with erythropoietin: 1-year follow-up study. Nephron 2000; 86: 200-201

20. DeVita MV, Frumkin D, Mittal S, Kamran A, Fishbane S, Michelis MF. Targeting higher ferritin concentrations with intravenous iron dextran lowers erythropoietin requirement in hemodialysis patients. Clin Nephrol 2003; 60: 335-340

Received for publication: 10.3 .06

Accepted in revised form: 19.6.06 